\title{
A favela tem nome próprio: a (re)significação do local na linguagem do funk carioca
}

\author{
The Favela has its own name: the \\ resignification of place in the language \\ of funk carioca
}

Adriana Carvalho Lopes*

Universidade Estadual de Campinas - Unicamp

Dizem que nós somos violentos, mas desse jeito eu não aguento.

Dizem que lá falta educação, mas nós não somos burros não.

Dizem que não temos competência, mas isso sim que é violência.

(Rap da Cidade de Deus. MCs Cidinho e Doca)

\begin{abstract}
RESUMO: O funk é uma prática musical produzida e consumida, principalmente, pela juventude das favelas do Rio de Janeiro. Além de diversão e trabalho, o funk é uma forma de identidade para essa juventude. Neste artigo, conjugo a análise linguística com a prática etnográfica para demonstrar que tal identidade possui uma linguagem específica, por meio da qual os artistas do funk significam as suas próprias experiências e, assim, constroem uma nova cartografia para a cidade do Rio de Janeiro. Nessa linguagem, a favela deixa de ser o espaço genérico da barbárie e se transforma em território com nome próprio e no local da habitação e de hábitos cotidianos de inúmeros jovens favelados.
\end{abstract}

PALAVRAS-CHAVE: funk, diáspora africana, identidade, linguagem, raça, espaço.

ABSTRACT: Funk carioca is a popular type of music in Brazil, produced and consumed mainly by the youth in the slums of Rio de Janeiro, known as favelas. More than entertainment and work, funk is a form of identity for the youngsters dwelling in the favelas. This paper combines linguistic analysis with ethnography in order to demonstrate that identities forged along such lines rely on a specific language in which funk performers re-signify their own social experiences and build a new cartography of the city. In such language, the slum is no longer a

*driclopes@ig.com.br 
space of barbarism. It is instead a neighborhood where many of these young people live and enact their everyday practices.

KEYWORDS: funk, African diaspora, identity, language, race, space.

Neste artigo, pretendo tratar do que é conhecido, nacionalmente, como funk carioca, uma prática musical produzida e consumida, principalmente, pela juventude das Favelas da Cidade do Rio de Janeiro. ${ }^{1}$ Apesar da designação no singular, a identidade do funk carioca é altamente heterogênea. Para alguns MCs e DJs, ${ }^{2}$ o funk é diversão, trabalho e sensualidade. Para outros é vibração, um ritmo que ninguém segura, mas também é a realidade e a linguagem da favela, denúncia e movimento cultural. Assim, realizo um recorte para dialogar com o que é considerado por alguns funkeiros como a origem, ou melhor, a raiz de toda essa diversidade que constitui a identidade do funk carioca atual. Para tanto, primeiramente situo o meu lugar de fala teórico e político no qual assumo que a realidade e as identidades são práticas sociais que também são construções discursivas. Analisar uma prática social é, portanto, interpretar e dialogar com práticas linguísticas atravessadas por historicidade (cf. MAGALHĀES, 2000; CHOULIARAKI; FAIRCLOUGH, 1999; MOITA LOPES, 2006). Posteriormente, contextualizo o funk carioca como uma manifestação local da diáspora africana, que, nos últimos vinte anos, vem sendo (re)atualizada e (re)significada em torno de todo o globo através da disseminação do hip-hop. E, por fim, analiso letras e relatos de MCs do Rio de Janeiro que (re)significam as condiçōes materiais das favelas, constroem para si uma identidade espacialmente orientada e reivindicam uma cartografia diferente para a cidade do Rio de Janeiro, relacionada com a forma pela qual os espaços desta cidade são hierarquizados, ou melhor, implicitamente racializados. ${ }^{3}$

\footnotetext{
${ }^{1}$ Apenas um relato de MC, ora apresentado, foi retirado da internet, pois o restante foi coletado em trabalho de campo realizado, em 2008, nas Favelas de Acari e da Rocinha, localizadas na Cidade do Rio de Janeiro.

2 Sigla que foi disseminada pela cultura hip-hop para designar os dois principais artistas na performance musical: o Mestre de Cerimônia e o Disc Jockey.

${ }^{3}$ Utilizo uma forma verbal e não um nome, pois não focalizo a "raça", os "brancos" ou os "negros" como se estas fossem categorias apriorísticas ou ontologias a-históricas. Assim como Wade (2000), interpreto "processos de racialização" num contexto onde as identidades raciais são frequentemente ambíguas, mutáveis e relacionais. Segundo Hall (2003), identidades são processos historicamente produzidos, nos quais os significados raciais constituem-se, à medida que interseccionam-se com outros eixos de identificação: por exemplo, gênero, classe, nação, etc.
} 


\section{O Funk Carioca: uma questão linguística}

Assim como alguns autores da Linguística Aplicada e da Pragmática Linguística, situamos a nossa discussão no interior de uma Linguística que é entendida como "um campo de estudos" - tais como estudos feministas, teoria queer, estudos latino-americanos, etc. -, que reúne pesquisadores de diversas áreas, focalizando temas em comum (MOITA LOPES, 2006, p. 97). Como mostra Pennycook (2006), sob a influência das criticas pós-colonial e pósmoderna e, ainda, da consequente "virada linguística" "nas ciências sociais, esse campo passa a privilegiar temas como a produção da identidade / alteridade, que até então eram estranhos à linguística ${ }^{5}$ (cf. MOITA LOPES, 2002, 2006; RAJAGOPALAN, 2003; PENNYCOOK, 2001). Tal interesse está relacionado com a compreensão de que a linguagem tem um papel fundamental na inteligibilidade dos problemas sociais contemporâneos, pois a dominação colonial foi (e continua sendo) não só econômica como também simbólica.

Nesse campo, compreendemos que o social não é uma dimensão que pode (ou não) ser adicionado à linguagem, pois é dela uma parte constitutiva. Ainda que a vida social não seja reduzida a uma dimensão discursiva, entendemos que seja impossível ter acesso a qualquer realidade que não seja constituída linguisticamente. A linguagem não é um elemento independente da vida social ou uma expressão de um único indivíduo possuidor de uma razão cartesiana. De acordo com Rajagopalan (2003), a linguagem é uma forma de ação social e política, ou seja, é uma prática dialógica na qual os sujeitos fornecem sentidos para si próprios e para o mundo. A significação não é exterior às condições materiais, pois é através da linguagem que os sujeitos fornecem "vida" ao mundo material. Assim, a linguagem é uma prática por meio da qual as identidades são

\footnotetext{
${ }^{4}$ Para Hall (2003), a virada lingüística tem a ver com a ênfase no sentido na definição de cultura, uma vez que essa deixa de ser entendida como um produto e passa a ser compreendida como um processo: uma prática de produção e troca de sentidos diversos entre membros de uma sociedade ou grupo. Para Weedon (1987, p. 21), a partir da virada linguística, a linguagem passou a ter um papel fundamental nas ciências sociais, pois essa passou a ser entendida como o lugar onde as formas reais e possíveis de organização social e suas consequências políticas e sociais são definidas e contestadas. ${ }^{5}$ Como mostra Pennycook (2006, p. 77), a virada linguística "reverberou em muitas áreas de investigação social, da sociologia à psicologia, da história à geografia." Contundo, tal virada teve pouco impacto na linguística, uma vez que a linguagem passou a ser reivindicada como um fenômeno fundamentalmente social, colocando em questão o próprio saber sobre a língua constituído no interior das fronteiras disciplinares da linguística.
} 
constituídas e determinada realidade espacial é apreendida, delimitada e compartilhada. Portanto, entender uma questão social como a forma pela qual os jovens das favelas significam a sua própria realidade espacial e a identidade do funk carioca é também compreender uma questão linguística.

Essa compreensão tem efeitos importantes na própria prática de pesquisa. Se a realidade é constituída linguisticamente, não há para a pesquisadora um lugar neutro exterior à linguagem. Trata-se de um tipo de pesquisa reflexiva que busca não só pensar sobre a linguagem, mas pensar na linguagem. Como argumenta De Certeau (2008, p. 69), nenhum discurso "pode sair da linguagem e colocar-se à distância para observá-la e dizer o seu sentido." Consequentemente, nesse campo, não buscamos um ponto de vista transcendental situado acima das práticas linguísticas, mas, sim, um engajamento político e ético com elas.

Formas híbridas de reflexão, de pesquisa e de prática formam esse campo de estudos. Portanto, ele é constituído por uma transdisciplinariedade tanto teórica quanto metodológica. Assim, neste texto, estabeleço conexóes entres dois tipos de práticas interpretativas: certa análise linguística e uma interpretação etnográfica, uma vez que o meu interesse é dialogar com o ponto de vista dos sujeitos que estão inseridos no mundo funk. Cabe destacar que esse diálogo não é entendido como uma comunhão mística entre pesquisados e pesquisadora; tampouco como uma mera projeção da investigadora, mas, sim, como uma negociação cuidadosa e, acima de tudo, afetiva entre os sujeitos envolvidos na pesquisa dentro de configurações particulares de poder.

\section{A linguagem do Funk Carioca}

O funk carioca é uma performance híbrida resultante de um intenso processo de apropriação, transformação e nacionalização da cultura hip-hop: uma das maiores expressões juvenis contemporâneas da diáspora africana. Ainda que a definição do que venha a ser a cultura hip-hop e a diáspora africana seja altamente contestada, assumo, como Paul Gilroy (1996, p. 175), que o hip-hop seria uma espécie de contradiscurso da diáspora africana. Ele funciona como uma prática de compensação à exclusão do letramento e política formais a que foram submetidos os descendentes de escravos no ocidente. Tal contradiscurso é propagado através da música e está relacionado com a construção de identidades de jovens habitantes de territórios urbanos que são marcados por formas similares, mas não idênticas, de racismo, pobreza e segregação espacial. 
Em minha análise, aproximo esse contradiscurso ao que De Certeau (2008) chamou de "antidisciplina", ou seja, as maneiras de fazer "microbianas" dos usuários (consumidores ou dominados) que acabam por deturpar ou lesar sistemas de dominação. Os contradiscursos seriam então um tipo de "tática" utilizada por esses grupos marginalizados no interior de um discurso hegemônico. ${ }^{6}$ O prefixo "anti" sinaliza modos de resistência linguísticos dessa cultura diaspórica. Não se trata, porém, de procurar nessas "táticas" uma resistência que supere - de uma vez por todas - as formas de dominação, mas de compreender as maneiras pelas quais os sujeitos no interior desse sistema inventam pequenas estratégias simbólicas de sobrevivência, modificando e (re)significando o sistema e suas representaçôes, de modo que eles operem em seu favor.

Uma vez que esse contradiscurso é diásporico, é preciso assumir toda a sua heterogeneidade, pois não é a origem comum que delimita, simbolicamente, a diáspora africana, e sim um compartilhamento de experiências marginais e subalternas. O hip-hop é uma linguagem que se dissemina e assume configurações específicas de acordo com o contexto no qual é performativizada. ${ }^{7}$ Portanto, vista por este ângulo diásporico, a transformação do hip-hop-uma performance híbrida desde seu início ${ }^{8}$ - em funk carioca não evidencia uma

\footnotetext{
${ }^{6}$ Assim como Laclau (1985), assumo que hegemonia é o predomínio de um grupo majoritário sobre outro. Ainda de acordo com esse autor, a hegemonia dá-se no campo da ideologia e um discurso torna-se hegemônico quando seu autor consegue fazê-lo ouvido, repetido e aceito pelos demais. No entanto, a hegemonia nunca é totalizante e está sempre envolvida num processo agonístico, que faz com que o seu consenso seja sempre temporário.

${ }^{7}$ Nesse sentido, não é necessário, como argumenta Vianna (1988, p. 109), buscar uma ancestralidade africana original comum entre a música eletrônica negra norteamericana e o ritmo dos subúrbios negros do Rio de Janeiro para estabelecer uma identificação entre ambos. A diferença é a marca da diáspora. Gilroy (1996, p. 25) destaca que, como toda a música negra da diáspora, o hip-hop é organizado por formas híbridas e mutantes, que se adaptam às forças e aos prazeres locais.

${ }^{8}$ Aqui vale lembrar dois aspectos do hip-hop. Como mostra Rose (1994), o hip-hop sempre foi uma prática musical que reunia tradições vernaculares não só de jovens afro-americanos mas também da juventude jamaicana, caribenha e latina que residia na cidade de Nova York. Um segundo aspecto é que, apesar de práticas musicais jovens como o funk, o reggae jamaicano, o samba-reggae na Bahia serem construções locais de representaçõoes culturais juvenis originariamente anglo-saxãs, não é exato afirmar que esses países seriam o centro dessas culturas juvenis. Como mostra Ari Lima (2002), num contexto global, a música é para os negros um símbolo afro-diaspórico
} 
mera importação cultural de um ritmo estrangeiro, mas demonstra as (re)invenções e as (re)novações de ritmos negros que sempre pulsaram nas favelas cariocas. Por essa via, vale destacar um fragmento do relato do poeta, líder comunitário e militante do Movimento Cultural "Funk é Cultura", Deley de Acari. Para ele, o "funk é uma música eletrônica da diáspora africana; uma música herdeira da "Cultura Black" estadunidense, mas também herdeira das nossas formas culturais tradicionais negras como a umbanda, o samba, o candomblé." Nesse relato, o poeta ressalta como o funk carioca é fruto de uma cultura negra que está para além das fronteiras nacionais. Assim, assumo que o funk é uma linguagem, resultante de um contínuo processo de incorporação e transformação, que conjuga novos elementos da cultura negra diaspórica às práticas locais. A musicalidade é uma das principais características dessa linguagem que desafia as fronteiras dos estados-nação com seus padrões de ética e estética.

\section{A "raiz" do funk}

Tradicionalmente a palavra "raiz" é utilizada como metáfora que indica certa estabilidade espacial ou uma anterioridade de um sujeito - seja ele coletivo ou individual - que se desenvolve numa linha temporal. Porém, não é nesse sentido que compreendo a raiz do funk. Parto do pressuposto de que interpretar a "raiz" de uma identidade é dialogar com reivindicações de sujeitos inseridos em estruturas de poder. Assim, a "raiz" não é uma essência original de um passado incontestável, mas, sim, uma reivindicação política e, portanto, estratégica do presente.

Em meados dos anos 2000, alguns MCs, que tiveram o início de suas carreiras na década de 1990, perdem completamente o espaço na "indústria cultural funkeira": ${ }^{10}$ suas novas músicas já não tocam mais nas rádios e nos

que dispensa centro-periferia. Assim, a despeito dos aspectos etnomusicológicos locais, tais práticas musicais poderiam ter se originado na Jamaica, em terras anglosaxãs ou no Brasil.

${ }^{9}$ Fragmento de um dos depoimentos coletados em pesquisa de campo na favela de Acari, em 2008.

${ }^{10}$ Aqui me refiro às rádios, aos programas de televisão e às casas de show que tocam funk na cidade do Rio de Janeiro, que movimentam, segundo pesquisa da Fundação Getúlio Vargas, realizada entre 2007 e 2008 e divulgada no Jornal Folha de S.Paulo, cerca de $\mathrm{R} \$ 10$ milhôes por mês. 
programas de televisão que divulgam o funk carioca. Esses MCs também não encontram mais espaço para tocar em casas de show destinadas ao público funkeiro. Segundo muitos produtores e DJs de funk, isso se deu pela mudança que houve no funk nos últimos sete anos. Se na década de 1990 os chamados "rap-funk" predominavam nos bailes e nas casas de shows cariocas, atualmente o que se consome nesses espaços é praticamente o que é conhecido como as "montagens". Essas últimas possuem uma base musical chamada de "tamborzão" e as letras são compostas por não mais de três versos de conteúdo altamente sensual. Os "rap-funk", por sua vez, são constituídos por grandes narrativas que são acompanhadas pela batida conhecida como "volt-mix". ${ }^{11}$

O lançamento das músicas desses MCs na década de 1990 coincidiu com o surgimento do funk nacional. Aliás, esses foram os artistas que gravaram as primeiras musicas de funk na cidade do Rio de Janeiro. A maior parte deles produz "rap-funk" até os dias atuais, mas só tiveram um sucesso "relâmpago" no passado com, apenas, duas ou três produções musicais.

Excluídos dessa indústria funkeira, esses MCs juntam-se e começam a reivindicar uma memória ou uma "raiz" para o funk. De acordo com esses MCs, os raps produzidos por eles, na década de 1990, são a "verdadeira raíz do funk". Tais músicas surgiram nos concursos chamados "Festivais de Galera", realizados por várias equipes de som que existiam na cidade. A identidade das galeras era determinada por territórios, que podiam coincidir ou não com uma favela. Os festivais eram compostos por várias etapas e uma delas era a etapa do rap. Para esse grupo de pessoas, esses raps, além de falar na linguagem da favela, também reproduzem a realidade sobre a favela. Em uma das entrevistas realizadas com um desses artistas, ele define a si próprio e a raiz do funk da seguinte maneira:

[n]ós somos a raiz do funk, mas não somos MCs da antiga como muita gente fala. Antiga pra mim é museu (...) Nós somos a raiz do funk porque falamos a verdade sobre o pessoal favelado do Brasil, falamos da nossa comunidade (mas não só da nossa), mas o que todas as comunidades (independente [sic] de credo, cor e religião) pedem. Porque é a mesma coisa, a mesma realidade que fere aqui sangra lá. E a gente fala de tudo. Não somos hipócritas, a gente fala bem da favela porque é a nossa casa, mas a gente fala que não tem apoio de ninguém. Só quem pode contar isso é a gente. ${ }^{12}$

${ }^{11}$ Essa definição é feita pelos próprios MCs e DJs do funk carioca.

${ }^{12}$ Depoimento coletado em pesquisa de campo na Favela de Acari, em 2008. 
Assim, o argumento que determina a identidade de "raiz" do funk é menos temporal e mais espacialmente orientado. Não é tanto a antiguidade que define essa raiz, mas, sim, o local a partir do qual se fala e sobre o quê se fala. Não se trata, apenas, de falar na linguagem da favela, mas de pertencer e, consequentemente, possuir legitimidade para falar sobre ela.

Interessante notar que mesmo sendo uma manifestação da diáspora africana não é uma "originalidade" explicitamente racial que define a raiz ou a autenticidade do funk carioca. No entanto, isso não quer dizer que os significados raciais não estejam ali presentes. "Raça" não é um conceito fixo que exista, independentemente, do discurso que o produz. Segundo Hall (1997), raça é um significado mutável e intrinsecamente relacionado com as formas de constituição e de exclusão de determinados sujeitos do mundo moderno. Portanto, ao analisar as práticas linguísticas não busco identificar como a "raça", os "brancos", os "negros", etc. são significados, mas, sim, como determinados sujeitos e práticas são implícita ou explicitamente racializados. Segundo Blackledge (2008), esse processo de racialização tem como característica principal a construção discursiva da desigualdade. Uma vez que a discussão sobre "a raça" como a base para a diferenciação entre grupos já não é mais politicamente aceitável, outros termos são frequentemente empregados para marcar determinados sujeitos e práticas como "a diferença." Neste texto, assumo que a racialização é um processo simbólico de discriminação do discurso hegemônico, que atribui às favelas e aos sujeitos favelados certas características, situando-os como alienígenas, perigosos, bárbaros, etc. Nesse discurso a referência à raça ou a qualquer critério racial não são explicitamente mencionados.

Os significados raciais, por exemplo, sempre foram dissimulados nas representaçōes das favelas e dos favelados não só na literatura sociológica produzida nas décadas de 1950 e 1960 como também na canção popular. Nessas representaçōes, a favela é sinônimo de pobreza e ser favelado é sinônimo de ser pobre (OLIVEIRA; MARCIER, 2006, p. 81). Ainda que a maior parte dessa população favelada seja negra, os significados raciais estão ali de forma silenciada.

A favela é um território marginalizado, construído no interior de uma sociedade fundada no mito da democracia racial. Como mostra Flauzina (2008), tal mito foi utilizado não só para interditar a formação de uma identidade negra no Brasil como também para apagar o conflito de raça existente na nação. Um dos vestígios desse conflito seria a segregação espacial, que lançou a população negra para as periferias de todo o país. Nesse sentido, 
poderíamos entender a favela como resultado de uma divisão racial, que, no discurso hegemônico, opera de forma silenciosa. Segundo Pinho (2003), no contexto brasileiro, o racismo só tem eficácia simbólica por meio de sua dissimulação, uma vez que a exclusão racial foi substituída pela retórica nacional de mestiçagem brasileira. Assim é possível um racismo sem sujeito (os racistas) e sem objeto (os negros).

Mesmo com as mudanças recentes sobre o pensamento racial no Brasil, a cidade do Rio de Janeiro, que serviu de palco para a invenção da nacionalidade e, logo, da mestiçagem brasileira, reitera continuamente tais silêncios nas leituras que são feitas sobre os territórios desta cidade: que situam "do lado de cá", a cidade maravilhosa, a terra do samba, das belas praias e do carnaval e, "do lado de lá", as favelas e seus perigosos sujeitos. O preconceito contra os sujeitos e o "lado de lá" da cidade parece não colocar em xeque o mito da democracia racial. É como se a hierarquização sobre determinados territórios da cidade não ameaçasse o mito da "sociabilidade carioca" que celebra a democracia e indistinção de "classes, cores e culturas". Em uma cidade onde a mistura de raça é simbolicamente (re)atualizada, o discurso hegemônico silencia a referência à distinção de cores, substituindo-a pela distinção do local de origem - isto é, do local onde se mora.

Entretanto, o sujeito que enuncia o discurso hegemônico não tem um controle soberano sobre a disseminação de seus sentidos (BUTLER, 1997). Assim, o mesmo discurso que oprime e constitui certos sujeitos como subalternizados, fornece, paradoxalmente, a possibilidade de existência e signos de resistência para esses sujeitos. A identidade não é um referente prédiscursivo livre da historicidade desses discursos, mas é por ela determinada. ${ }^{13}$ Já que o racismo, nesse discurso, não se confessa, é o estigma sobre o local de origem que a linguagem do funk apropria-se para (re)significá-lo. Assim, é possível compreender como funk carioca reivindica a sua raiz sem fazer mençōes explícitas aos significados raciais. No funk carioca, há a reivindicação de uma origem espacial constitutiva de uma identidade que pode ser vista como

13 Segundo Butler (1997), a resistência não está relacionada com a liberação transcendente do sujeito de uma certa ordem discursiva, mas, sim, com uma política de subversão por meio da qual a agência dos sujeitos abre a possibilidade para uma (re)significação radical dos discursos. Eu acrescentaria a isso uma (re)significação do discurso hegemônico, fazendo com que esse opere em favor dos grupos subalternizados. 
metonímia ${ }^{14}$ da identidade negra na cidade do Rio de Janeiro, a identidade "favelada."

Aqui vale lembrar que movimento semelhante ocorre com o hip-hop estadunidense. Segundo Forman (2004, p. 207), o hip-hop reivindica o hood como a sua autêntica raiz. Tal termo é etimologicamente derivado da palavra neighborhood (vizinhança), mas desenvolveu seus próprios significados. $\mathrm{O}$ hood representa o "solo" do gueto onde brota a autêntica cultura urbana negra. Diferentemente do funk, esse hip-hop possui significados raciais explícitos. Se a raiz do hip-hop - o gueto, o hood - formou-se em uma sociedade marcada pela segregação racial, a raiz do funk - a favela - é um território constituído no interior de uma sociedade fundada no mito da democracia racial.

\section{A favela como espaço do funk}

Nesta sessão faço uma alusão ao artigo "A palavra é: favela", de Oliveira e Macier (2006, p. 90), em que a "favela é tratada como espaço do samba." Segundo as autoras, nenhum outro ritmo produzido na favela foi "capaz de produzir uma identidade espaço-música." Porém, os funkeiros de um modo geral reconhecem que, atualmente, para muitos jovens a favela é enunciada menos como o espaço do samba e mais como o local do funk. Aqui, vale destacar um dos depoimentos de MC Leonardo em que ele contrasta os compositores de samba com os de funk.

Outro dia o repórter perguntou pra gente assim: "por que a poesia da favela acabou?" Eu falei: "Pô, você vive em que planeta, meu irmão? (...) Quer que eu pegue o violão e vá falar "Alvorada lá no morro que beleza"? Não! Você está falando da poesia de Cartola, de Noel? (...) Só essa galera que é poesia pra você? Porque eu coloco MC Dolores, Cidinho e Doca como os atuais poetas da favelas. São sim e me incluo nessa também. ${ }^{15}$

\footnotetext{
${ }^{14}$ Refiro-me à figura retórica que possibilita deslocar uma parte para significar o todo. Assim, o que é enunciado como o objeto do preconceito são imagens identitárias que se associam, silenciosamente, ao corpo negro (seja a imagem do pobre, do favelado, do marginal, do funkeiro etc.). Tal operação retórica perpetua o racismo sem que ele seja explicitamente identificável.

${ }^{15}$ Depoimento retirado do filme "Favela On Blast", gravado na Rocinha no ano de 2008. Disponível em: <http://www.youtube.com/watch?v=SoKgV9u75lc>. Acesso em: jan. 2009.
} 
MC Leonardo destaca que, atualmente, os principais artistas da favela não são sambistas, mas, sim, os funkeiros: Dolores, Cidinho e Doca. Ele cita um verso da música do sambista Noel Rosa "alvorada lá no morro que beleza" de forma irônica para contestá-lo, pois já não são mais esses versos que retratam e representam a forma pela qual os jovens veem e experienciam a favela.

Esses funkeiros começam a cantar a "favela" num momento em que esta é significada no discurso hegemônico como um todo homogêneo dominado pelo tráfico; um discurso que generaliza e atenua completamente qualquer oposição que possa haver entre aqueles que seriam bandidos e aqueles que seriam moradores. Segundo Peralva (2000), desde 1980, a favela é vista e reconstruída pela classe média como o oposto da cidade, como o espaço inimigo, onde qualquer forma de violência do Estado é legítima.

As representações dos grupos hegemônicos não acionam imagens de favelas no plural, mas, sim, a imagem de uma única entidade totalizante. Como se esses territórios estivessem situados em uma outra cidade, utilizam um olhar que não enxerga as práticas cotidianas e concretas que por lá circulam. Como se os sujeitos que lá habitam não fossem tão sujeitos, criam um discurso que silencia as vozes locais e delimitam os "territórios favelas" como um espaço genérico do perigo e da barbárie ligada, única e exclusivamente, ao tráfico de drogas. Porém, no funk, cada favela tem nome próprio e é significada como um local heterogêneo e de habitação. Em outras palavras, a linguagem do funk "dá sentido"16 à favela: "fazendo ver" outros mapas e "desenhando" diferentes percursos na Cidade do Rio de Janeiro. O funk veste com nome próprio cada favela e os espaços no interior dela.

Como mostram alguns autores da geografia cultural, o espaço não é uma entidade física, inocente e apolítica. De acordo com Lefebvre (1991, p. 26), o espaço é uma prática discursiva determinante na constituição das identidades sociais. Partindo desse pressuposto, alguns autores fazem uma distinção entre "espaço" e "lugar", produzida socialmente, útil para compreender a forma pela qual determinados sujeitos não só interagem como também se situam e significam o mundo. De acordo com Forman (2002, p. 25), ambos possuem uma relação dialógica, mas, ao passo que o "lugar" é definido pela interação humana local imediata, o "espaço" mostra as trajetórias mais amplas e genéricas. De forma semelhante, De Certeau (2008) argumenta que o local é uma prática que se constrói no ato de caminhar pela cidade e o espaço no ato onividente

\footnotetext{
${ }^{16}$ Aqui utilizo tal termo em sua dupla acepção: tanto como o significado de algo, como também para designar uma direção.
} 
de observar, medir e delimitar. ${ }^{17}$ Segundo De Certeau (2008), essas práticas locais e espaciais são como atos de fala que constroem mapas das cidades.

Se o discurso hegemônico aciona atos de fala para constituir e delimitar a favela como um "espaço" dominado pelo tráfico de drogas, os MCs com os seus atos de fala líricos fornecem um outro tipo de existência para esses territórios. Estes passam a ser o "local" do funk, onde os bailes e as práticas que o constituem são detalhadamente enunciados. Um exemplo notório dessa identidade é o rap "Endereço dos Bailes", dos MCs Junior e Leonardo, em que os artistas "fazem ver" um outro mapa do Rio de Janeiro, como mostro a seguir.

Endereço dos Bailes

(Junior e Leonardo)

No Rio tem mulata e futebol,

Cerveja, chopp gelado, muita praia e muito sol, é...

Tem muito samba, Fla-Flu no Maracanã,

Mas também tem muito funk rolando até de manhã

Vamos juntar o mulão e botar o pé no baile $D j$

Ê ê ê ah! Peço paz para agitar,

Eu agora vou falar o que você quer escutar

Ê ê ê ê! Se liga que eu quero ver

$\mathrm{O}$ endereço dos bailes eu vou falar pra você

É que de sexta a domingo, na Rocinha, o morro enche de gatinha

Que vem pro baile curtir

Ouvindo charme, rap, melody ou montagem,

É funk em cima, é funk embaixo,

Que eu não sei pra onde ir

O Vidigal também não fica de fora

Fim de semana rola um baile shock legal

A sexta-feira lá no Galo é consagrada

A galera animada faz do baile um festival

Tem outro baile que a galera toda treme

É lá no baile do Leme, lá no Morro do Chapéu

Tem na Tijuca um baile que é sem bagunça

A galera fica maluca lá no Morro do Borel

${ }^{17} \mathrm{O}$ local está para o caminhante, assim como o espaço está para o cartógrafo. 
Ê ê ê ah! Peço paz para agitar,

Eu agora vou falar o que você quer escutar

Ê ê ê ê! Se liga que eu quero ver

$\mathrm{O}$ endereço dos bailes eu vou falar pra você

Vem Clube Íris, vem Trindade, Pavunense

Vasquinho de Morro Agudo e o baile Holly Dance

Pan de Pillar eu sei que a galera gosta

Signos, Nova Iguaçu, Apollo, Coelho da Rocha, é...

Vem Mesquitão, Pavuna, Vila Rosário

Vem o Cassino Bangu e União de Vigário

Balanço de Lucas, Creib de Padre Miguel

Santa Cruz, Social Clube, vamos zoar pra dedéu

Volta Redonda, Macaé, Nova Campina

Que também tem muita mina que abala os corações

Mas me desculpa onde tem muita gatinha

É na favela da Rocinha lá na Clube do Emoções

Vem Coleginho e a quadra da Mangueira

Chama essa gente maneira

Para o baile do Mauá

O Country Clube fica lá praça seca

Por favor, nunca se esqueça,

Fica em Jacarepaguá

Ê ê ê ah! Peço paz para agitar,

Eu agora vou falar o que você quer escutar

Em "Endereços dos Bailes", os artistas fazem mais do que uma descrição dos bailes. Enfatizando os aspectos positivos dessa diversão, eles realizam um convite aos olhos. O Rio de Janeiro deixa de ser visto apenas como o espaço genérico do samba, do futebol e da praia - os tão consagrados símbolos nacionais -, para ser também o local onde acontecem inúmeros e específicos bailes funk. Num momento em que os MCs buscavam dar visibilidade e legitimidade ao funk, eles acabaram por fazer o mesmo com o local em que este era produzido e consumido. Tais locais passam a ser enunciados como parte integrante da cidade.

Vários funks produzidos na década de 1990 têm nome de favelas específicas, por exemplo, o Rap da Rocinha, Rap do Vidigal, Rap da Cidade de Deus. Da mesma maneira, muitos MCs do "funk de raiz" também eram conhecidos como representantes de certa galera ou de uma favela específica, 
como William e Duda do Borel, Galo da Rocinha, Mascote do Vidigal, etc. O nome dos raps e dos artistas de funk indica um referencial comunitário. Os artistas de funk existem publicamente como um sujeito coletivo "da Rocinha", "do Vidigal", etc.; e, ainda, enunciam em nome de suas próprias favelas ou comunidades. ${ }^{18}$ Nessas poesias, os aspectos positivos das favelas são reiterados, à medida que os MCs nomeiam as ruas, esquinas e os lugares de entretenimento de cada um desses locais, como mostro no rap a seguir.

\section{Rap do Vidigal e da Rocinha}

(Mascote e Galo)

E aí MC Galo, como é que tá a Rocinha?

Um paraíso onde tem muitas mulheres.

E o Vidigal?

Vidigal é um Morro de Lazer, em frente ao mar

Quem sobe não quer mais descer

Vai, vai, vai, vem, vem, vem

Quem dança no Vidiga, dança na Roça também

O Vidigal é um morro de valor

É uma favela que o Papa batizou

Comunidade humilde, é um morro muito shock

É lá que mora o MC Mascote

A Rocinha é uma comunidade linda

É a maior favela da América Latina

Se liga sangue bom, preste atenção

No que eu te falo

É lá que mora o tal do MC Galo

Se liga amigos, não me leva a mal

Agora eu vou falar das áreas do Vidigal

Subindo a escola vai parar no Barracão

Subindo sempre tem, você para no Cantão

${ }^{18}$ Atualmente, os funkeiros já não utilizam, como na década de 1990, nomes de favelas específicas nos funks, pois enunciar o pertencimento a uma delas pode ser entendido como enunciar o pertencimento a certa facção criminosa. Tal fenômeno deve-se ao um aumento da violência no mercado varejista de drogas diretamente relacionado ao acirramento, nos últimos quinze anos, de uma política de Estado que criminaliza a pobreza e as favelas cariocas (MALAGUTI, 2003). 
Passa Rua Três, Rua Nova, Orelhão

Logo mais em cima, tem a associação

Tem que continuar subindo no sapatinho

Se de repente lombra, você corta o caminho

Olha, meus amigos, eu não vou perder a linha

Agora eu vou falar é das área da Rocinha

Vem a Rua 1, a Rua 2 e a Rua 3

E também a Rua 4 não se esqueça de vocês

Cachopa, Pocinho, Vila Verde, Terreirão,

Cidade Nova, Curva do S e Fundação

Vem a Via Ápia, Paulo Brito e Boiadeiro

Roupa Suja e o Valão sempre tem que vir primeiro

Vidigal tem conceito, a Rocinha pede a paz

Vidigal tem conceito, a Rocinha pede a paz

Neste rap, dois MCs estabelecem um diálogo em que cada um narra as práticas espaciais de seus locais de habitação: as favelas do Vidigal e da Rocinha. Cada MC, na posição de locutor, situa-se como caminhante que mais do que "fazer ver" um determinado local, propõe um itinerário. Por exemplo, os MCs evidenciam as favelas com nome e características positivas próprias, "Rocinha, um paraíso", "Vidigal, um morro de Lazer", mas também o percurso que realizam em seus locais de habitação, "Subindo a escola vai parar no Barracão", "Logo mais em cima, tem a associação."

Buscando entender esse ponto de vista local, tão cantado nos "raps de raiz", que conheci e caminhei por diversas favelas do Rio de Janeiro, quase sempre na companhia desses MCs. Por meio da interpretação etnográfica, procurei compreender cada local, dialogando com a perspectiva daqueles que lá sempre me receberam. Desde o início de minha caminhada percebi que, apesar das condições materiais das favelas causarem indignação em seus moradores, elas também são locais capazes de gerar um enorme sentimento de orgulho e pertencimento nos sujeitos que lá habitam. Tal sentimento é enunciado nas letras de funk. Por meio delas, os MCs travam verdadeiras batalhas linguísticas contra o discurso hegemônico em que a favela é construída como o espaço de atos de atrocidade com condições desoladoras. No rap "Cidade de Deus", ${ }^{19}$ os

${ }^{19}$ Esse rap foi gravado em 2003, um ano depois do lançamento do filme "Cidade de Deus", dirigido por Fernando Meirelles. Esse filme popularizou e projetou a "Cidade de Deus", internacionalmente, como o espaço da barbárie e de uma violência brutal. 
MCs Cidinho e Doca encenam atos de fala que se constituem como uma reposta contestatória ao discurso hegemônico, conforme mostro no fragmento a seguir.

\section{Cidade de Deus}

(Cidinho e Doca)

C-I- D- A- D- E- D- E- D- E- U- S

e vê se não esquece de Deus

êêêêê Cidade de Deus

C-I- D- A- D- E- D- E- D- E- U- S

e vê se não esquece de Deus

êêêêê Cidade de Deus

Cidade de Deus

Dizem que nós somos violentos,

mas desse jeito eu não aguento.

Dizem que lá falta educação, mas nós não somos burros não.

Dizem que não temos competência, mas isso, sim, que é violência.

Que só sabemos fazer refrão

se liga sangue bom,

mas não é assim.

Nós temos escola

nós temos respeito

se quer falar de nós

vê se fala direito.

Estou documentado doutor

cidadão brasileiro e tenho o meu valor.

Meu pai é pedreiro; mamãe, costureira

e eu cantando rap pra massa funkeira

O ritmo é quente é alucinante

êta povo do funk, êta povo gigante.

$\mathrm{Eu}$ quero ouvir geral no refrão

Cidade de Deus êêêêê Cidade de Deus

C -I- D- A- D- E- D- E- D- E- U- S

e vê se não esquece de Deus

êêêêê Cidade de Deus

C -I- D- A- D- E- D- E- D- E- U- S

e vê se não esquece de Deus

êêeêêe Cidade de Deus

Cidade de Deus 
Mas se tu não sabe, eu te conto, mas eu não sei se tu está pronto.

Nem tudo o que falam é verdade.

Queremos paz, justiça e liberdade.

Quando tiver um tempo sobrando,

se liga no que estou falando.

Vai lá conhecer minha cidade.

Eu vou te dizer aí que começa,

tu vai se amarrar, vai se divertir

Depois que tu entrar não vai querer sair.

Vai ver alegria, vai ver sofrimento

Não escondemos nada do que temos lá dentro.

Porque a comunidade tem fé

A vida que levamos é tipo maré.

As vezes tá alta, as vezes tá baixa,

quem sabe navegando essa maré se acha.

Esqueça a caneta, escreva de lápis.

Quando a maré mudar, você passa a borracha.

Porque a vida do povo é assim,

às vezes tá tranquila e às vezes tá ruim.

(...)

O rap tem início com o refrão em que os MCs soletram o nome da Favela Cidade de Deus ( $C-I-D-A-D-E-D-E-D-E-U-S)$ e depois repetemno inúmeras vezes, ao longo da música. A palavra "Deus" é enfatizada (vêse não se esquece de Deus). Nesse momento, os MCs fornecem pistas sobre quem é o seu interlocutor: o sujeito que não só poderia esquecer o atributo "de Deus", como também associar essa Cidade a um atributo oposto (nem tão Divino)! A música é uma resposta / defesa daqueles que vivem nas favelas para aqueles que estão fora delas. De um lado, temos os MCs que narram em primeira pessoa para marcar uma enunciação em nome de um sujeito coletivo: o "nós da Cidade de Deus". Mesmo quando eles enunciam na primeira pessoa do singular, trata-se de um reforço dessa coletividade, uma vez que eles acionam representaçōes paradigmáticas da forma pela qual os músicos significam o sujeito da favela: não como o "bandido", mas como um cidadão brasileiro, músico, filho de pais trabalhadores (estou documentado, doutor / cidadão brasileiro / tenho o meu valor / meu pai épedreiro / mamãe, costureira). De outro lado, temos o interlocutor, aquele sujeito que não é da favela, significado ora como "doutor", ora como "sangue bom". Esse último termo é uma gíria do 
chamado "favelês" ${ }^{20}$ que designa uma forma de tratamento amigável com o outro. O "sangue bom" é explicitamente convidado a conhecer a Cidade de Deus (Se Liga no que eu estou falando/vai lá conhecer a minha cidade).

Logo após o refrão, os MCs citam certas imagens tipicamente acionadas no discurso hegemônico (ou no "discurso do doutor") sobre a favelas: o espaço da violência e da falta (Dizem que nós somos violentos / Dizem que lá falta educação / Dizem que não temos competência). Enunciando como um coletivo, os MCs citam tal discurso para contestar atos de fala que, violentamente, interpelam e constituem a favela e seus sujeitos, unicamente, por estereótipos violentos (Mas desse jeito eu não aguento, mas nós não somos burros não, mas isso, sim, que é violência).

Nesse rap, não só os aspectos positivos das favelas são significados. Ainda que a "raiz" do funk tenha o "local favela" como uma categoria central na organização de suas narrativas, não se trata de um "espaço idealizado", retratado por apenas uma perspectiva. Muito pelo contrário, os "rap-funk de raiz" não só mostram os aspectos positivos do "local" favela mas também funcionam como denúncia social. Ao fazer o convite ao "doutor", os MCs realizam uma caminhada, em que mostram as dificuldades de se viver numa favela (vai ver alegria, vai ver sofrimento / não escondemos nada do que temos lá dentro). É sob o ponto de vista do sujeito que vive as práticas locais, tecendo contornos e trajetórias das favelas, que os aspectos positivos e negativos desse território são narrados, transformando a habitação e o hábito em algo que vale a pena lutar.

Parafraseando o rap, trata-se de uma trajetória vulnerável, que "só pode ser escrita a lápis" (Esqueça a caneta escreva de lápis / Quando a maré mudar você passa a borracha). No entanto, tal trajetória é o destino de milhares de sujeitos que, nesse rap, são (re)escritos: o favelado, que no discurso hegemônico é interpelado como uma perigosa estereotipia, aqui é significado como um "sujeito de direito", ou melhor, como "povo" brasileiro (porque a vida do povo éassim / às vezes tá tranquila, às vezes tá ruim).

\footnotetext{
${ }^{20}$ Segundo Facina (2008), esse termo foi publicizado pelo rapper MV Bill e explicita um aspecto típico da cultura carioca: "a existência de uma língua produzida a partir das interações sociais que ocorrem nas favelas e que impõem gírias e modas linguísticas ao conjunto dos habitantes das cidades."
} 


\section{Considerações finais}

Nesta análise não pretendi ser imparcial nem neutra, não olhei para os atos de fala dos MCs como se esses tivessem uma "superfície linguística" 21 que garantisse a objetividade de minha análise; tampouco, caminhei pelos locais de habitação desses artistas, tentando situar o meu olhar por "sobre os seus ombros" 22 . Este texto é resultado de uma observação politicamente comprometida em mostrar visões alternativas de mundo, em que o diálogo com as reivindicaçôes de sujeitos marginalizados servem como um tipo de denúncia contra as generalizaçôes e silêncios do discurso hegemônico e, para além disso, colocam-se como vozes dissonantes capazes de mostrar outros sentidos sobre os sujeitos e a realidade social.

Ao dialogar com esses sujeitos, percebi que apesar de o funk carioca possuir uma identidade altamente heterogênea, havia um fio condutor que me levaria a um aspecto fundamental dessa identidade. No entanto, para encontrá-lo foi necessário analisar linguisticamente as músicas produzidas por esses funkeiros, sempre conduzida pela prática etnográfica. Conjugando esses dois exercícios interpretativos, é que pude perceber como a "raiz-favela" é uma construção linguística central para a identidade desses artistas. Como um movimento de (re)significação política, a favela - marginalizada e, implicitamente racializada no discurso hegemônico - é reescrita como "raiz" na linguagem do funk. A "raiz-favela" transforma-se não só numa forma de existência social para esses MCs dentro e fora da indústria funkeira, mas, além disso, a "raiz-favela"

${ }^{21}$ Já que não há um exterior à linguagem, o exercício interpretativo de destacar certos "índices linguísticos" para analisá-los não é fundamentado por uma razão objetiva, mas por um diálogo politicamente situado.

${ }^{22}$ Aqui faço referência ao princípio etnográfico de Geertz (1978). Segundo esse antropólogo, para compreender corretamente a realidade pesquisada, é preciso interpretála, sob o ponto de vista dos nativos, ou metaforicamente, "sobre os ombros dos nativos." No entanto, é necessário assumir que a interpretação realiza-se em várias direçōes: não só o pesquisador "olha sobre os ombros do nativo" como também esse último olha sobre os ombros do pesquisador (CLIFFORD, 2002). Portanto, aqui, não apresento uma análise que seria exatamente "o ponto de vista dos sujeitos do funk", mas teço uma narrativa fruto de um diálogo entre diversos pontos de vista; um diálogo que é comprometido com a transformação da realidade social, principalmente no que diz respeito à forma pela qual as fevelas e os favelados são representados no discurso hegemônico. 
é a possibilidade de um outro tipo de reconhecimento público para esses locais e seus sujeitos.

As narrativas dos raps "de raiz" são constituídas por atos de fala que os MCs narram e constroem a forma pela qual esses "micromundos" são vividos e experienciados não só por eles, mas pela maioria dos jovens das favelas. $\mathrm{O}$ funk traz à tona para a sociedade a favela como o local onde as pessoas se divertem ao som do funk, mas também o local onde elas habitam. Por meio dessa linguagem altamente localizada, eles enunciam e fazem valer as experiências de um grande contingente de jovens que habitam as favelas; jovens que ora são silenciados, ora são estigmatizados no discurso hegemônico. Como diz MC Leonardo, "o funk carioca é uma poderosa arma porque é uma forma de comunicação que mostra o que nós favelados vivemos, pensamos e queremos." 23

\section{Referências}

BITTENCOURT, B. Funk movimenta R 10 milhões por mês só no Rio de Janeiro, diz estudo. Folha de S.Paulo, São Paulo. Disponível em: <http:// www1.folha.uol.com.br/folha/ilustrada/ult90u492067.shtml.> Acesso em: 27 jan. 2009.

BLACKLEDGE, A. The racialization of language in British political discourse. Critical Discourse Studies, v. 3, n. 1, p. 61-79, 2006. Disponível em: <http:// www.informaworld.com/smpp/title - content $=t 713695016>$. Acesso em: maio 2008.

BUTLER, J. Excitable speech: a politics of the performative. New York: Routledge, 1997.

CHOULIARAKI, L.; FAIRCLOUGH, N. Discourse in the late modernity: rethinking critical discourse analyse. Edimburgo University Press, 1999.

CLIFFORD, J. A experiência etnográfica. Antropologia e literatura no século XX. José Reginaldo Santos Gonçalves (Org.). 2. ed. Rio de Janeiro: Editora UFRJ, 2002.

DE CERTEAU, M. A invenção do cotidiano. Artes de Fazer. Trad. Ephraim Ferreira Alves. Petrópolis, RJ: Vozes, 2008.

FLAUZINA, A. Corpo negro estendido no chão. O sistema penal e o projeto genocida do Estado brasileiro. Rio de Janeiro: Contraponto, 2008.

${ }^{23}$ Depoimento coletado na Rocinha no ano de 2008. 
FORMAN, M. Represent: Race, Space and Place in Rap Music. In: FORMAN, M.; NEAL, M. (Org.). That's the Joint. The hip-hop studies reader. New YorkLondon: Routledge, 2004. p. 201-223.

. The hood comes first. Race, Space and Place in Rap and Hip-hop. Middletown, CT: Wesleyan University Press, 2002.

FACINA, A. "Vou te dar um papo reto": linguagem e questōes metodológicas para uma etnografia do funk carioca. ENCONTRO NACIONAL DE LINGUAGEM E IDENTIDADE, 1, Nov. 2008, Campinas. Anais... Campinas: Instituto de Estudos da Linguagem, IEL-Unicamp, 2008.

GEERTZ, C. A interpretação das Culturas. Rio de Janeiro: Zahar, 1978.

GILROY, P. The Black Atlantic. Modernity and Double Consciousness. 4. ed. Cambridge: Massachusetts, 1996.

HALL, S. Representations: Cultural representations and signifying practices. California: Sage Publications, 2003.

. Cultural identity and diaspora. In: WILLIAMS, P.; CHRISMAN, L. Colonial Discourse and Post-colonial Theory: a reader. New York: Columbia University Press, 1997. p. 392-404.

LACLAU, E.; MOUFFE, C. Hegemony and socialist strategy: towards a radical democratic politics. London: Verso, 1985.

LEFEBVRE, H. The production of space. Oxford: Basil Blackwell, 1991.

LIMA, A. Funkeiros, timbaleiros e pagodeiros: notas sobre juventude e música negra na cidade de Salvador. Caderno Cedes, Campinas, v. 22, n. 57, p. 77-96, 2002.

MAGALHÃES, I. Eu e tu: a constituição do sujeito no discurso médico. Brasília: Thesaurus, 2000.

MALAGUTI, V. Difíceis ganhos fáceis. Drogas e juventude pobre no Rio de Janeiro. 2. ed. Rio de Janeiro: Revan, 2003.

MOITA LOPES, L. P. Identidades fragmentadas. A construção discursiva de raça, gênero e sexualidade em sala de aula. Campinas, SP: Mercado das Letras, 2002. MOITA LOPES, L. P. (Org.). Por uma Linguística Aplicada indisciplinar. São Paulo: Parábola Editorial, 2006.

OLIVEIRA, J. S. de; MACIER, M. H. A palavra é: favela. In: ZALUAR, A.; ALVITO, M. Um século de Favela. 5. ed. Rio de Janeiro: Editora FGV, 2006. p. 61-115. 
PENNYCOOK, A. Uma Linguística aplicada transgressiva. In: MOITA LOPES, L. P. (Org.). Por uma Linguística Aplicada indisciplinar. São Paulo: Parábola Editorial, 2006.

PENNYCOOK, A. Global Englishes and Transcultural Flows. London and New York: Routledge, 2007.

PERALVA, A. Violência e democracia. O paradoxo brasileiro. São Paulo: Paz e Terra, 2000.

PINHO, O. O mundo negro: sócio-antropologia da reafricanização em Salvador. 2003. 302 f. Tese (Doutorado em Antropologia) - Faculdade de Ciências Humanas, Universidade Estadual de Campinas, Campinas, 2003.

RAJAGOPALAN, K. Por uma linguistica crítica. Linguagem, identidade e a questão ética. São Paulo: Parábola Editorial, 2003.

ROSE, T. Black Noise. Rap Music and Black Culture in Contemporary America. Middletown, CT: Wesleyan University Press, 1994.

VIANNA, H. O mundo funk carioca. Rio de Janeiro: Jorge Zahar, 1988.

WADE, P. Music, Race and Nation. Música Tropical in Colombia. Chicago: The University of Chicago Press, 2000.

WEEDON, C. Feminist Practice and Poststructuralist Theory. Oxford: Basil Blackwell, 1987.

Recebido em fevereiro de 2009. Aprovado em junho de 2009. 